\title{
Personalidade aUtoritáRIa e Pesquisa empírica COM A Escala F: ALGUNS ESTUdOS BRASILEIROS*
}

\author{
Authoritarian personality and empirical research with F Scale: some \\ brazilian studies
}

\begin{abstract}
Resumo Prossegue-se neste texto a análise da relação presente no estudo de Adorno et al. (1950) entre tendências de personalidade, ideologia e preconceito. Para isso, são expostos dados de pesquisas com universitários com a Escala $\mathrm{F}$ e a relação dessa escala com outras, criadas a partir de questões geradas naquele estudo: Escalas de Ideologia da Racionalidade Tecnológica, Traços Narcisistas de Personalidade e Manifestações de Preconceito Moral e contra Pessoas com Deficiência. Verificou-se, por meio dessas pesquisas que: a) a Escala $\mathrm{F}$ continua fidedigna e válida para os nossos dias; b) traços do sadomasoquismo têm correlação com a adesão à ideologia da racionalidade tecnológica, com o narcisismo e com os dois tipos de preconceito considerados; c) as medidas de personalidade antidemocrática, narcisismo e da adesão a uma maneira de pensar formal e sistemática estão correlacionadas com as duas formas de preconceito estudadas, mas as características de personalidade autoritária estão mais relacionadas com o preconceito moral do que contra pessoas com deficiência, ocorrendo o oposto com as características de personalidades narcisistas. Conclui-se que o sadomasoquismo ainda exerce papel acentuado na constituição de preconceitos e que as necessidades psíquicas subjacentes a esses distintos preconceitos podem ser diferençadas, necessitando de formas diversas para serem combatidos.
\end{abstract}

Palavras-chave: Personalidade autoritária. Escala F. PreconCEITO.

ABSTRACT The analysis of the relationship present in the study by Adorno et al. (1950) between tendencies of personality, ideology and prejudice is continued. To do this, it exposes research data with university students with the F-scale and presents its relationship with others created from questions generated in that study: Technological Rationality Ideology, Narcissistic Personality Traits and Manifestations of Moral Prejudice and against People with Disabilities. It was verified through these surveys that: a) Scale F remains reliable and valid for our days; b) traits of sadomasochism are correlated with adherence to the ideology of technological rationality, with narcissism and with the two types of prejudice considered; c) measures of antidemocratic personality, narcissism and adherence to a formal, systematic way of thinking are correlated with the two forms of prejudice studied, but cha-

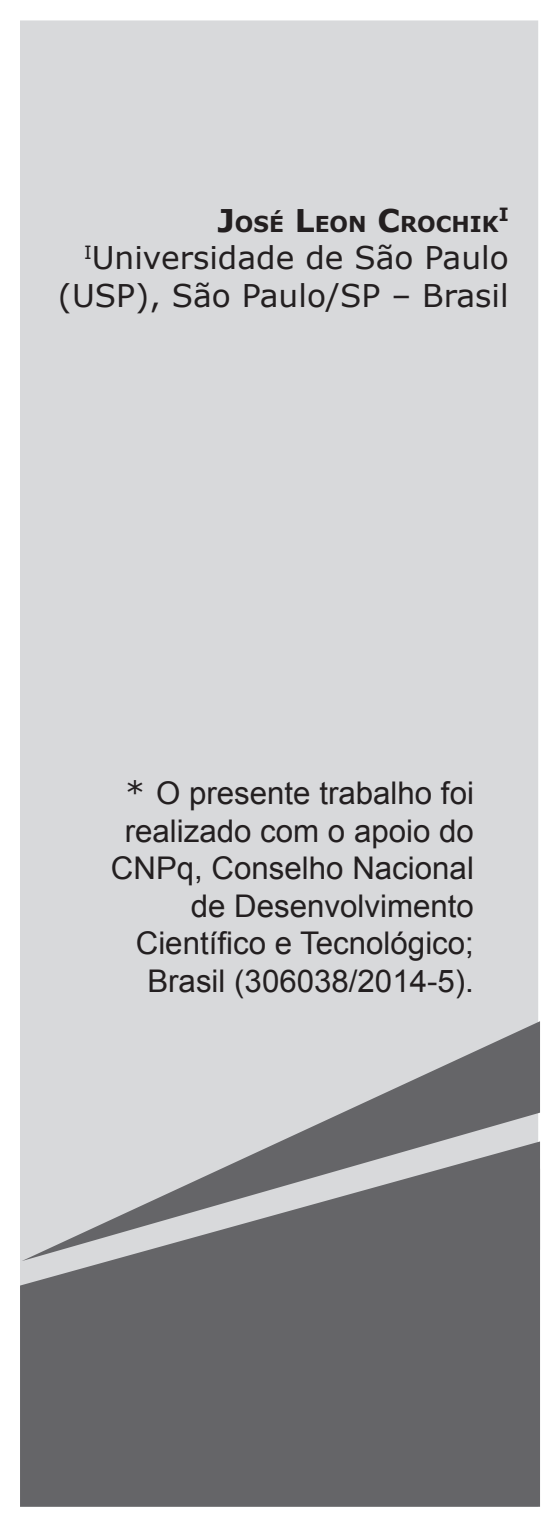


racteristics of authoritarian personality are more related with moral prejudice than with persons with disabilities prejudice, occurring the opposite with the characteristics of narcissistic personalities. It is concluded that sadomasochism still plays a significant role and that the psychic needs underlying the prejudices may be different, requiring different ways of combating them. KEY-WORDS: AUTHORITARIAN PERSONALITY. F SCALE. PREJUDICE.

$\mathrm{O}$ uso de métodos derivados de investigações sociais empíricas para a compreensão do que pode ter ocasionado a adesão individual a formas de pensar contrárias à própria vida e para, consequentemente, poder combater os regimes sociais totalitários, foi recomendado por Horkheimer e Adorno (1973). Não deixaram, contudo, de apontar para contradições presentes na utilização destes métodos: expressar pela frieza dos números a redução dos indivíduos a coisas que, por sua vez, também se expressam pela ausência de sentimentos propícios à experiência; ter de se pôr como neutro na investigação sobre o horror. Essas contradições, como defendem, devem ser vividas na prática e a autocrítica do emprego de tais métodos e a crítica aos próprios métodos precisam estar sempre presentes. Deve-se, para enfrentar a frieza contemporânea dos indivíduos que auxiliou na manutenção do fascismo, entender o que a gerou.

Segundo esses autores, os indivíduos reproduzem as grandes leis sociais, o que indica o necessário entendimento de motivos psicológicos presentes na adesão já referida: a que propicia a defesa do que não é racional. Conforme Adorno (2015), o comportamento econômico e racional, do ponto de vista social - a motivação para o lucro -, é mediado pelo medo individual de ser expulso da coletividade que pode defender o indivíduo da destruição; no entanto, segundo Horkheimer e Adorno (1985), esse medo continua a existir na substituição do domínio da natureza sobre ele pelo domínio da sociedade, que, nesse sentido, reage ainda a forças não civilizadas. Aliás, esse mesmo diagnóstico a respeito da civilização foi feito por Freud (2011) na antevéspera da eclosão do Nacional Socialismo alemão no início da década de 1930.
A primeira questão que se coloca neste texto é a referente à manutenção desta sociedade por meio de indivíduos que são parcial ou plenamente alheios a ela. Em outros termos, se a autoconservação, impulsionada pelo medo, é o motivo psicológico que leva o indivíduo a aderir a ideias e ideais que permitem sua preservação imediata, mas o condenam a uma vida sem sentido, pois alheia a si mesmo, até que ponto pode-se afirmar que ele, por suas ações, reproduz a sociedade? Tem-se que pensar em um indivíduo cindido, portanto, não indivisível e não indivíduo, que, como Horkheimer e Adorno (1973) indicam, é aquele capaz de fazer substância de si próprio, tendo consciência de que é mediado socialmente. Para a reprodução social indicada, o indivíduo pode contribuir com ou sem consciência da irracionalidade que reproduz. No entanto, em ambos os casos, o que seria propício ao indivíduo para que se torne sujeito - fazer substância de si mesmo - deve ser negado.

Se, como na análise que Adorno e Simpson (1994) fizeram acerca da música popular, o fanático é aquele que defende o que repudia, mas se vê obrigado a defender, o fanatismo poderia ser definido como a formação reativa - no sentido psicanalítico - de um sentimento que deve ser evitado: a rejeição se tornar aceitação exagerada e vice-versa; a consciência é constantemente afastada do que critica, voltando-se também aos outros que criticam o objeto idolatrado.

Como alternativa, o indivíduo pode fazer a escolha do mal menor, e não afastar a percepção de que (re)age contra os seus princípios e desejos. Esse tipo de indivíduo talvez represente aquele que é nomeado de danificado, por Adorno (2015), que é capaz de resistir ao todo. Não é plenamente integra- 
do à sociedade, e não age por meio de uma negação indeterminada: tenta preservar o que é propício a uma vida civilizada. Ao expressar o conflito que vive, não reproduz plenamente a sociedade, ao contrário, mostra as suas forças repressivas.

Freud (2011) analisa como a adesão ao conteúdo ideacional religioso pode ocorrer. A criança cedo descobre que o amado pai não poderá protegê-la de tudo, gerando um sentimento de insegurança; se a ideia desse pai protetor, no entanto, puder ser projetada em um pai grandioso eterno, onipresente e onipotente, a renúncia a si mesmo em nome dos grandes desígnios religiosos pode ocorrer, uma vez que esse conteúdo ideacional desde cedo seja repetido. Isso permite, segundo esse autor, evitar a neurose, uma vez que se fortalece uma ilusão coletiva, que por ser defendida por muitos toma o lugar da verdade. Nessa análise, nota-se a possibilidade da incorporação de ideias coletivas calcadas em necessidades individuais: no caso, ser protegido da destruição.

Os preconceituosos, segundo Horkheimer e Adorno (1973), também trazem motivos psicológicos que levam à perseguição de minorias. O pensamento estereotipado, que é repetitivo, padronizado e formulado por divisões simples, mas fatais para os indivíduos visados, permite justificar perseguições e evitar que os motivos que levam a essas perseguições sejam conscientes. Esses autores enfatizam que fenômenos sociais, como o fascismo, não podem ser reduzidos à motivação psicológica. A compreensão dessa motivação, contudo, ajuda a entender e combater aqueles fenômenos, pois não deixam de ser um momento deles.

Determinações objetivas de características psíquicas propícias à defesa de regimes sociais totalitários, como o fascismo do século XX, foram, conforme Horkheimer e Adorno (1973; p. 173): “...a desintegração da propriedade média, a crescente impossibilidade de uma existência econômica autossuficiente, certas transformações na estrutura da família e certos erros na direção da economia".
O capitalismo dos monopólios, o declínio da autoridade, dado também devido ao enfraquecimento de instituições sociais importantes para a formação individual, como a família, a escola, a religião, são fatos que contribuíram para tornar frágil a constituição do indivíduo, tornando-o propício a aderir a ideologias totalitárias. Na análise que Horkheimer e Adorno (1985; p. 189) fizeram do antissemitismo, essa transformação do capitalismo e as consequências sobre a formação individual também são realçadas: no período liberal do capitalismo concorrencial, o indivíduo, como exposto pela psicanálise, constituído pela dinâmica conflituosa entre id, ego e superego, que garantia alguma autonomia, foi substituído por um indivíduo frágil, inapto a ter experiências e, por isso, precisa de indicações sociais para guiá-lo. Nas palavras dos autores:

A psicanálise apresentou a pequena empresa interior que assim se constituiu como uma dinâmica complicada do inconsciente e do consciente, do id, ego e superego. No conflito com o superego, a instância de controle social no indivíduo, o ego mantém as pulsões dentro dos limites da autoconservação. As zonas de atrito são grandes e as neuroses, os faux fraix dessa economia pulsional, são inevitáveis. Não obstante, a complicada aparelhagem psíquica possibilitou a cooperação relativamente livre dos sujeitos em que se apoiava a economia de mercado. Mas, na era das grandes corporações e das guerras mundiais, a mediação do processo social através das inúmeras mônadas mostra-se retrógrada. Os sujeitos da economia pulsional são expropriados psicologicamente e essa economia é gerida mais racionalmente pela própria sociedade.

Essa "gestão" de comportamentos e decisões individuais ocorre por meio de líde- 
res, que podem ser representados e expressar ideários políticos, sociais, que a partir de uma análise simplificada do mundo, indicam o que pode ou não ser feito. Nesse sentido, a compreensão da fragilidade individual e sua busca por proteção, que, por sua vez, pode se tornar perseguição a outros considerados mais frágeis ainda, possibilitaria frear a violência individual induzida por regimes sociais totalitários. E, de fato, Horkheimer e Adorno (1973) propõem que o conhecimento a respeito de como se constitui a personalidade autoritária pode ser uma medida contra a perseguição de minorias.

Em seu estudo sobre a personalidade autoritária, realizado nos Estados Unidos da América, na década de 1950, Adorno et al. (1950) pesquisaram as relações entre tipos de estruturas psíquicas, posições políticas-econômicas e preconceito; para isso, utilizaram diversos meios: escalas com itens do tipo Likert; teste psicológico e questões projetivas; entrevistas. Pelo uso de correlações estatísticas dos escores obtidos pelas escalas, verificaram que as motivações relacionadas à estrutura psíquica autoritária estão mais relacionadas com a perseguição das minorias do que com as posições dos sujeitos sobre a economia e a política. Em outros termos, os escores da Escala do Fascismo (Escala F) estavam mais relacionados com os escores das escalas que avaliaram o Antissemitismo e o Etnocentrismo, do que com os escores da Escala do Conservadorismo Político e Econômico. Os que tendiam, conforme as dimensões da Escala F, à agressão e submissão autoritárias, ao pensamento estereotipado, à superstição, ao moralismo sexual, ao cinismo, a ser sadomasoquistas também tendiam a ter altos escores nas escalas acerca do preconceito, e vice-versa; houve também, correlação de menor magnitude, mas ainda assim significante, entre o conservadorismo político econômico e o preconceito. Por meio dos escores obtidos nessas escalas, foi possível selecionar os que tinham mais e os que tinham menos tendências sadomasoquistas e preconceituosas e classificá-los como personalidades autoritá- rias e personalidades não autoritárias, as últimas mais flexíveis na estrutura de sua constituição, mas nem por isso, sempre livres de defenderem pensamentos estereotipados.

No estudo acerca da personalidade autoritária, esta não é, em geral, nomeada de sadomasoquista, mas como antidemocrática. As dimensões presentes na Escala $\mathrm{F}$ e parte do referencial teórico adotado - obras de W. Reich e de Erich Fromm - para compô-la, no entanto, indicam que não é equivocado entender que as expressões personalidade antidemocrática e sadomasoquista possam ser intercambiáveis. A análise que Adorno faz do tipo nomeado de "autoritário" (ADORNO et al., 1950) indica a necessidade psíquica masoquista de se punir por ter desejos contrários à moralidade não de todo introjetada e, por essa mesma incompletude, necessitar, por sadismo, punir os outros, que passam a representar desejos que deve negar em si mesmo . Horkheimer e Adorno (1973, p. 178-179) mostram a admiração desse tipo de personalidade pelas hierarquias sociais:

O pensamento e a sensibilidade dessas pessoas estão orientados hierarquicamente, submetem-se à autoridade moral idealizada do grupo a que julgam pertencer - o 'in-goup', (...) e estão continuamente alertas para condenar, sob os mais diversos pretextos, os que se encontram fora do grupo ou aqueles a quem se considera inferiores. A expressão popular alemã 'Radfahrernatur' (tradução literal: "natureza ciclista”, na acepção metafórica de uma pessoa que gosta de calcar com o pé quem está por baixo e, ao mesmo tempo, dobra o corpo, em posição humilde, para os que estão acima [N. do T.]) descreve com muita exatidão essa atitude.

Por isso, neste texto, entendemos que a Escala $\mathrm{F}$ avalia também a estrutura psíquica própria ao sadomasoquismo. 
Horkheimer e Adorno (1973, p. 181) indicaram que determinada forma de pensar nomeada de Mentalidade do Ticket - era mais propícia à personalidade autoritária do que ideologias que chamaram de "fabricadas". Essa forma de pensar é mais adequada para a adaptação a uma sociedade burocratizada e mecanizada, e diz respeito ao enfraquecimento da pessoa para decidir sobre si mesma, sobre o seu destino. Em relação a essa forma de pensar, afirmam esses autores:

O processo de mecanização e burocratização exige de quem se encontra submetido a ele um novo tipo de ajustamento. Para enfrentar quaisquer exigências que surgem em qualquer setor da vida, é preciso que, em certa medida, os próprios indivíduos se mecanizem e padronizem. (...) Não só a utilização de estereótipos e juízos de valores preestabelecidos permite que a vida se torne fácil e faz com que o interessado seja para os chefes uma pessoa digna de confiança, mas também possibilita uma orientação mais rápida e liberta da excessiva fadiga que está ligada à penetração das complexas relações da sociedade moderna.

Com base em diversos textos dos frankfurtianos - Horkheimer e Adorno (1985), Marcuse (1981 e 1982) e Habermas (1983), é possível pensar que serve de base para tal "estrutura de pensamento" a ideologia da racionalidade tecnológica que, em outra ocasião (CROCHIK et al., 2009, p. 127) foi definida da seguinte forma:

(...) essa ideologia diz respeito a uma forma de pensamento que utiliza a sistematização, a classificação, a normalização e o pragmatismo para analisar qualquer objeto em detrimento de suas particularidades - devidas a condições histó- ricas e sociais. (...) Para esta forma de pensar, cujo conteúdo é a forma, os diversos objetos não podem ser diferentes da forma pela qual são percebidos e refletidos pela razão instrumental.

Como já salientado, o formalismo presente nessa ideologia pode servir de base para a denominada mentalidade do ticket, mas não coincide com ela. É mais propriamente ilustrada pela redução da razão ocidental ao cálculo, pela pretensão que tudo seja conhecido de antemão, pois, segundo Horkheimer e Adorno (1985), o que está "fora" é ameaçador. Essa ideologia remete ao mito de que tudo volta à origem, de que tudo se repete, nada há de novo. Trata-se mais de uma limitação da razão do que de seu falseamento, ainda que uma razão que não se limite objetivamente como lógica do sujeito para apreensão dos objetos, que não se confundem com essa lógica, não possa ser verdadeira. Ela é própria ao cientificismo e tecnicismo vigente que pretende reduzir todo conhecimento à ciência e à técnica (CROCHÍK, MASSOLA e SVARTMAN, 2016).

Se a ideologia se transformou, e os conteúdos das opiniões podem estar associados mais com a forma do pensamento do que com posições políticas e econômicas, a estrutura de personalidade autoritária parece também ter se transformado em uma mais regredida: a personalidade narcisista. A primeira delas, a sadomasoquista, é própria da fase psicossexual anal, como descrita pela Psicanálise, ${ }^{1}$ já a narcisista, da fase psicossexual oral, anterior à outra. No narcisismo, o eu tenta se estruturar; no sadomasoquismo, busca sobreviver e ultrapassar os conflitos que lhe são próprios. Adorno $(1969 ; 2015)$ indica que o narcisismo tende a substituir as formas de personalidade predominantes na época de Freud - a histeria, a neurose obsessiva - e entendemos: o sadoma-

Os conceitos psicanalíticos utilizados neste texto são delimitados, sobretudo por Freud, e têm no trabalho de Laplanche e Pontalis (1988) uma bem desenvolvida apresentação. 
soquismo. Lasch (1983), estudioso que prosseguiu os estudos dos frankfurtianos, escreveu a respeito da cultura do narcisismo, proveniente também dos "fracassos" coletivos da década de 1960.

Adorno et al. (1950) tiveram como sua hipótese principal de trabalho que os indivíduos têm uma pauta ampla e coerente de convicções políticas, econômicas e sociais, que expressa tendências profundas da personalidade. Se a ideologia se alterou e a estrutura da personalidade mais frequente segundo as necessidades sociais da época também, caberia saber, em um primeiro momento, qual a relação das novas ideologia e estrutura de personalidade com as que estudaram: a personalidade autoritária e as ideologias políticas e econômicas conservadora e liberal.

Para isso, Crochík (2005) traduziu, adaptou e aplicou a Escala F, com 28 itens, e elaborou três outras escalas: ${ }^{2}$ uma escala de categorização política (escala C), numerada de zero a 10 pontos, com a palavra "esquerda" no início e "direita" ao final; entendeu-se que direita significava conservadorismo político-econômico e esquerda a necessidade de transformações sociais para a constituição de uma sociedade justa e igualitária; uma escala para avaliar a adesão à ideologia da racionalidade tecnológica e outra, com a Professora Maria de Fátima Severiano, para avaliar traços narcisistas de personalidade; as duas últimas escalas têm estrutura semelhante à da escala $F$, isto é, afirmações tipo Likert e um contínuo de seis pontos, sem a opção de neutralidade quanto à concordância ou não com essas afirmações. ${ }^{3}$

\footnotetext{
Os índices psicométricos dessas escalas foram satisfatórios e não serão reapresentados neste texto.

3 Em relação às pesquisas, cujos dados serão exibidos a seguir, as escalas com item do tipo Likert foram utilizadas, pois permitem diretamente a comparação com os dados obtidos por Adorno et al. (1950), que, além dessas escalas, também empregaram outros instrumentos, e porque o objetivo foi o de verificar quão geral é o fenômeno estudado, e não uma análise de camadas psíquicas que abranjam informações menos visíveis, permitida por meio de entrevistas e testes projetivos, por exemplo. Essa observação permite delimitar os resultados a serem apresentados, mas não deve eliminar a sua importância para a compreensão do fenômeno estudado.
}

Em 2001 e 2002, essas escalas foram aplicadas a 139 estudantes de cursos de Psicologia, Administração de Empresas e Enfermagem de uma universidade de São Paulo. Todas as escalas se correlacionaram significantemente com as outras ao nível de 0,01. Nesse sentido, pode-se supor que, ao lado da ideologia e da personalidade anteriores, surgiram novas, que não as substituíram, mas se constituem em outras possibilidades de estrutura de personalidade e de ideologia que podem estar subjacentes ao autoritarismo. Como a correlação da Escala F com a de categorização Política (Escala C) e com a escala da ideologia da racionalidade tecnológica foram maiores do que as correlações dessas escalas com a escala $\mathrm{N}$, pode-se supor que os conflitos próprios ao sadomasoquismo ainda sejam mais propícios para explicar a adesão a essas ideologias do que o narcisismo.

Em relação à ideologia da racionalidade tecnológica, em estudo anterior (CROCHÍK, 2000), a correlação entre a escala da ideologia da racionalidade tecnológica e a escala $\mathrm{F}$ já havia sido maior do que a encontrada entre essa ideologia e as características narcisistas de personalidade. Isso não implica que não tenha aumentado de frequência o tipo de personalidade narcisista, mas que essa se relaciona menos com adesão à ideologia da racionalidade tecnológica do que a personalidade autoritária.

Em síntese, pelos dados obtidos nas pesquisas mencionadas não é possível confirmar que houve substituição de um tipo de ideologia e de uma forma de estrutura de personalidade por outra ideologia e por outro modo de constituição psíquica. No entanto, pode-se supor o fortalecimento de uma nova ideologia e o aumento de frequência de indivíduos narcisistas. Essas não eliminaram as anteriores, e apresentam relações com elas: quanto mais um sujeito é conservador do ponto de vista político, tanto mais defende a ideologia da racionalidade tecnológica; quanto mais sua constituição psíquica se aproxima do sadomasoquismo, tanto mais é narcisista. Resta, a partir do estudo de Adorno et al. (1950) 
a respeito da personalidade autoritária, considerar a relação dessas variáveis com o preconceito, que eles avaliaram pelas escalas do antissemitismo e, posteriormente, pela escala do etnocentrismo, as duas relacionadas entre si e com os escores da Escala F.

Para verificar essa questão, foi criada, em parceria com o pesquisador Ricardo Casco, uma Escala de manifestação do preconceito que, com a Escala C, Escala F, com a Escala I, com a Escala $\mathrm{N}$, foi aplicada também àquela amostra testada em 2001 e 2002. Delimitou-se o conceito de preconceito como uma atitude hostil em relação a minorias. Como é uma atitude, essa contém, segundo Krech, Crutchfield e Ballachey (1975), um componente cognitivo - no caso, os estereótipos -, um componente emocional - gostar, odiar ou ser indiferente ao alvo -, e uma tendência para a ação - discriminação presente na segregação e na marginalização desse alvo (CROCHÍK, 2011; CROCHík et al., 2013).

Essa escala sobre preconceitos (Escala P) tem a mesma estrutura da Escala $F$, e se dirige a quatro alvos, com 12 afirmações para cada um deles: judeu, negro, pessoas com deficiência intelectual e pessoa com deficiência física. Foram obtidas correlações significantes com todas as demais escalas, com $p<0,01, a$ maior delas com a Escala $F(r=0,66)$, e, assim, pode-se afirmar que a tendência antidemocrática continua a se relacionar com o preconceito em nossos dias, mais do que os traços narcisistas de personalidade. Com esse resultado, pode-se supor que o preconceito é mais afeito à delimitação específica de alvos a serem atingidos, que configura o sadomasoquismo em sua ambivalência frente ao objeto amado e odiado simultaneamente, do que ao narcisismo que é considerado sem objetos para dirigir sua libido, além de seu próprio eu.

Deve-se ressaltar que a manifestação do preconceito também se relaciona com a ideologia da racionalidade tecnológica: quanto maior é a manifestação do preconceito, tanto mais o indivíduo defende a ideologia da racionalidade tecnológica. O pensamento estereotipado, próprio ao preconceito, parece se relacionar com uma visão de mundo sistemática, técnica e padronizada, evitando ambiguidades não suportáveis pelo indivíduo preconceituoso, para quem, de uma forma geral, tudo deve ser muito bem delimitado: quer a adesão a regras morais ou a eficiência exigida por nossa sociedade. Quem é moralmente suspeito ou não produtivo, por quaisquer motivos, pode-se tornar alvo do preconceito.

Se o preconceito é expressão imediata de um sistema autoritário, ele foi central no estudo sobre a personalidade autoritária, assim como em nossos estudos, e a determinação da estrutura de personalidade e da ideologia continua presente, mas agora, ao que parece, com uma variedade maior, quer de ideologias, quer de estruturas de personalidade.

Outra questão que se põe à luz desses estudos é se há uma única forma de preconceito dirigida indiferentemente a todos os grupos que se constituem como alvos ou se há preconceitos distintos em relação às diversas minorias. Em 2002, foi aplicada (CROCHÍK, 2004) a Escala de manifestação de Preconceitos a uma amostra de 172 estudantes universitários paulistanos, de um curso de Administração e de cursos de Ciências Biológicas, e foram correlacionados entre si os escores dessa escala dirigidos a cada um dos alvos que contempla (negro, judeu, pessoa com deficiência física, e pessoa com deficiência intelectual), em cada um desses cursos. Nas duas amostras, todas as subescalas se correlacionaram significantemente entre si, ao nível de 0,01, isto é, quem tem o preconceito em relação a um desses alvos tende a manifestá-lo também em relação aos demais.

$\mathrm{Na}$ amostra de estudantes do curso de Administração, as duas maiores correlações encontradas foram entre o preconceito dirigido contra pessoas com deficiência $(r=0,72)$ e entre o preconceito voltado contra as etnias $(r=0,52)$; na amostra dos alunos dos cursos de ciências biológicas, a maior correlação foi a encontrada no preconceito voltado contra pessoas com deficiência $(r=0,70)$, mas a correlação entre o preconceito voltado contra as duas etnias foi a mais baixa $(r=0,22)$. Pode- 
-se supor que o preconceito dirigido contra o judeu e contra o negro é constituído por características inexistentes nesses alvos, isso é, precisa de motivos criados para existir; já o preconceito dirigido às pessoas com deficiência se nutre de uma generalização indevida: julga que dada a deficiência, essa se estende para o que não é devido; em ambos os casos, há uma percepção distorcida da realidade que deve atender necessidades psíquicas e apelos ideológicos.

Assim, se, de fato, o preconceito se refere à pessoa que o desenvolve e não à sua vítima, não é menos verdadeiro que diferentes alvos podem suscitar diferentes reações nos preconceituosos, pois, caso contrário, a correlação dos diversos preconceitos seria plena, o que não deve significar, deve-se enfatizar, que $o$ alvo tenha qualquer responsabilidade sobre a violência que recai sobre si.

Pode-se supor, a partir dos resultados encontrados nas diversas pesquisas referidas, que diferentes estruturas de personalidade podem estar associadas a diferentes tipos de alvos do preconceito. É essa hipótese que será verificada pelo estudo a ser descrito, cujos dados ainda não foram publicados.

Um dos objetivos ${ }^{4}$ desta pesquisa foi verificar se a ideologia da racionalidade tecnológica, o sadomasoquismo e o narcisismo se relacionam com dois tipos de preconceito: contra pessoas com deficiência e o que envolve julgamentos morais.

Em 2016, foram aplicados para 135 estudantes universitários do Estado de São Paulo, cinco escalas, das quais três já foram descritas: Escala da Ideologia da Racionalidade Tecnológica (Escala I), com sete itens, a Escala do Fascismo (Escala F), com 28 itens, a Escala dos Traços Narcisistas de Personalidade (Escala N), com 10 itens; as duas outras escalas foram derivadas da Escala de Manifestação de Preconceitos (Escala P): uma escala de preconceito contra pessoas com deficiência (PD),

4 A pesquisa em questão tem mais objetivos do que aquele que será exposto neste texto. O projeto de pesquisa foi aprovado pelo Comitê de Ética do Instituto de Psicologia em 8 de setembro de 2015, Parecer n. 1.218.644. com seis itens, e outra contra minorias que moralmente são rejeitadas (PM), com quatro itens. Os itens dessas escalas encontram-se no Anexo 1.

Alguns dados referentes a essas escalas, aplicados nesta amostra, estão na Tabela 1.

Tabela 1: Dados referentes às escalas utilizadas

\begin{tabular}{cccc}
\hline Escalas & Média & $\begin{array}{c}\text { Desvio } \\
\text { Padrão }\end{array}$ & $\begin{array}{c}\text { Alpha de } \\
\text { Cronbach }\end{array}$ \\
F & 2,65 & 0,64 & 0,83 \\
I & 3,13 & 1,19 & 0,83 \\
N & 3,12 & 0,93 & 0,81 \\
PD & 1,82 & 0,97 & 0,82 \\
PM & 2,86 & 1,34 & 0,74 \\
\hline
\end{tabular}

Os dados da Tabela 1 indicam que todas as escalas têm um Alpha de Cronbach satisfatório, mesmo a que se refere ao Preconceito Moral. Considerando 3,5 pontos o centro de cada uma dessas escalas, podemos constatar que, em média, os estudantes dessa pesquisa têm escores próximos a esse ponto central na Escala I e na Escala N, e abaixo dele nas Escalas F, PD e PM.

Os sujeitos foram comparados considerando as suas características quanto aos escores nas diversas escalas. As alunas foram menos preconceituosas contra as pessoas que têm deficiência do que os alunos [ $\mathrm{t}$ (133) $=3,70 ; p=0,00]$. Os que alegam seguir religiões, quando comparados com os que indicaram não seguir qualquer religião, tiveram escores maiores na Escala $\mathrm{F}[\mathrm{t}(133)=4,37 ; \mathrm{p}$ $=0,00]$; na Escala $\mathrm{N}[\mathrm{t}(133)=2,20 ; \mathrm{p}=0,03]$, na Escala I $[\mathrm{t}=(133)=2,03 ; \mathrm{p}=0,04]$ e na Escala $\mathrm{PM}$ $[\mathrm{t}=(133)=3,42 ; \mathrm{p}=0,00]$. Os estudantes da área de Exatas tiveram maiores escores na Escala $F$ do que os da área de Humanas [F(2 e 132=6,24, $\mathrm{p}=0,00]$, e maiores escores na Escala do Preconceito Moral do que os seus colegas da área de Biológicas [ $\mathrm{F}(2$ e 132) = 4,88; $\mathrm{p}=0,01]$. Por fim, quanto maior o nível socioeconômico dos sujeitos, tanto maior o escore na Escala $\mathrm{N}$ $[r(133)=0,18 ; p=0,04]$ e tanto maior o escore na Escala PD $[r(133)=0,25 ; p=0,00]$. Ainda 
que esses dados indiquem questões importantes, essas não serão analisadas, uma vez que não se referem ao objetivo da pesquisa que foi apresentado. Essas informações serviram, no entanto, para se calcular correlações com controle para as variáveis: sexo, religião, área de estudo e nível socioeconômico.

Na Tabela 2, encontram-se as correlações parciais obtidas entre, de um lado, os escores das Escalas F, I e $\mathrm{N}$ e, de outro lado, os escores das escalas sobre o preconceito.

Tabela 2: Correlações parciais entre as escalas

\begin{tabular}{ccc}
\hline & $\begin{array}{c}\text { Preconceito } \\
\text { contra Pessoas } \\
\text { com Deficiência }\end{array}$ & $\begin{array}{c}\text { Preconceito } \\
\text { Moral }\end{array}$ \\
Fascismo & $0,45^{* *}$ & $0,51^{* *}$ \\
Narcisismo & $0,33^{* *}$ & $0,28 * *$ \\
Ideologia & $0,38^{* *}$ & $0,44^{* *}$ \\
Preconceito & $0,44^{* *}$ & \\
Moral & & \\
\hline
\end{tabular}

Todas as correlações constantes na Tabela 2 são significantes com $p<0,00$, o que significa que o sadomasoquismo, $\mathrm{o}$ narcisismo e a ideologia da racionalidade tecnológica são variáveis importantes para se entender e combater ambos os tipos de preconceito estudados. Cabe, no entanto, ressaltar que o sadomasoquismo, avaliado pela Escala $\mathrm{F}$, e a adesão à ideologia da racionalidade tecnológica estão mais relacionados com o preconceito moral do que o narcisismo, ocorrendo o inverso em relação ao preconceito contra pessoas com deficiência, ainda que, para ambos os tipos de preconceito avaliados, as magnitudes das correlações das Escalas F e I tenham sido mais elevadas.

Importante mencionar que houve também correlação significante entre os dois tipos de preconceito $[r(133)=0,44 ; p=0,00]$, o que confirma dados das pesquisas anteriores apresentadas (ADORNO et al., 1950; CROCHIK, 2004) que indicam que o preconceituoso tende a desenvolver vários tipos de preconceito, ao que se deve acrescentar as considerações sobre os dados anteriores que mostram que, se relacionam-se entre si, não o fazem plenamente, exibindo diferenças importantes entre si.

Em suma, as pessoas com traços narcisistas de personalidade tendem a ser mais preconceituosas contra indivíduos que apresentem deficiências e os que têm traços sadomasoquistas dirigem seu preconceito, sobretudo contra quem, segundo eles julgam, não age de forma moral adequada. Conforme Adorno et al. (1950) acentuam, a personalidade autoritária não conseguiu constituir satisfatoriamente a consciência moral, porisso precisa forçar a adesão a valores que não incorporou, mas que se associam com a autoridade, para a qual destinam um sentimento ambivalente: amam e odeiam; a perseguição àqueles que imaginariamente não seguem os valores pretensamente defendidos por essa autoridade ocorre para que os próprios desejos negados e o medo da autoridade não venham à tona. Já os narcisistas que consideram a aparência, sobretudo da perfeição, e a força quer física, quer intelectual como parte de seu próprio eu, que são respostas a um eu ferido em sua onipotência infantil, também desdenham nas pessoas com deficiência os que lutam em não perceber em si próprios: sua fragilidade.

Para concluir este texto, podemos mencionar, à luz dos resultados obtidos nos diversos estudos, que:

1 - a Escala do Fascismo continua fidedigna e válida para os nossos dias, o que indica a importância de estarmos atentos ao sadomasoquismo provocado pela sociedade atual, que sobrevaloriza a força e despreza o seu oposto;

2 - traços do sadomasoquismo, avaliados pela Escala $\mathrm{F}$, têm correlação com a adesão à ideologia da racionalidade tecnológica, com o narcisismo e com os dois tipos de preconceito considerados. Nesse sentido, não somente se pode afirmar que o sadomasoquismo continua a ser uma estrutura de personalidade existente, como apresenta consonância com traços narcísicos de perso- 
nalidade e com a ideologia que sustenta uma visão sistemática, nesse caso, tem prazer no poder demonstrado no "fazer coisas", "ser eficiente", como o tipo Manipulador, analisado por Adorno et al. (1950). A correlação do autoritarismo com os preconceitos avaliados mostra como fenômenos psíquicos não podem ser pensados independentemente de sua determinação social.

3 - as medidas de personalidade antidemocrática, narcisista e da adesão a uma forma de pensar que reduz todos os fenômenos à racionalidade técnica estão correlacionadas com as duas formas de preconceito estudadas, mas características de personalidade autoritária estão mais relacionadas com o preconceito moral do que contra pessoas com deficiência, ocorrendo o oposto com as características de personalidades narcisistas. Como já afirmado, para o sadomasoquista, a questão moral, expressa nos desvios em relação às regras não de todo introjetadas por ele e, por isso mesmo, exageradamente defendidas, é central; mais do que a questão da perfeição corporal ou intelectual, que, para o narcisista, é mais importante do que os supostos desvios morais. Para o narcisista, a questão da autoconservação, imaginária e realmente ameaçada, dada a sua constante sensação de impotência, à qual reage sua aparente prepotência, é mais premente.

Esses resultados indicam a importância de estudos empíricos para a continuidade da análise que os frankfurtianos fizeram de nossa sociedade que, ao se considerar a previsão de Horkheimer e Adorno (1985), no prefácio da segunda edição de a Dialética do Esclarecimento, mais aprofundou sua tendência para se converter em uma sociedade administrada do que se encaminhou para a liberdade de seus indivíduos. As configurações psíquicas estudadas, a ideologia da racionalidade tecnológica e o preconceito manifestado são nítidos sinais da prevalência de uma sociedade repressiva. O fato, no entanto, de os escores nas diversas escalas não terem sido elevados, assim como a magnitude das correlações encontradas entre elas, sinaliza sua contradição: luta pela liberdade e manutenção de mecanismos de opressão, que geram sofrimentos individuais e perseguição de diversos tipos. Para que essa contradição seja superada, a análise de tendências sociais continua essencial. Tal análise, no entanto, não pode ser reduzida à empiria, mas, sem essa empiria, pode-se não perceber com nitidez como o objeto se constitui na atualidade e, assim, ter meios adequados para a sua libertação.

Por fim, cabe retomar a indicação inicial deste texto referente à contradição própria ao uso de métodos quantitativos em ciências sociais, uma vez que esses, ao mesmo tempo que trazem dados importantes para a compreensão da sociedade e da constituição psíquica dos indivíduos, podem se converter em fetiche quando não se reflete sobre seus limites. O que permite tirá-los de uma interpretação que ofusca o que os determina é a análise teórica, lembrando que essa não deixa de ser, como Adorno (1995) defende, prática. Os tipos de personalidade, as formas de ideologia e as atitudes preconceituosas examinados neste texto não poderiam ter sido concebidos, testados e analisados sem uma teoria da sociedade e sem uma psicologia social analiticamente orientada, como a delimita Adorno (2015). Assim, não demonstram apenas as tendências encontradas, mas apontam também para as que, teoricamente, pela análise histórica da sociedade, já são passíveis de se tornarem reais, opondo-se à regressão social e psíquica existente. 


\section{REFERÊNCIAS}

ADORNO, T. W. "Opinión, locura, sociedade." In: . Intervenciones: nueve modelos de critica. Caracas: Monte Avila ed, 1969.

. "Sobre a relação entre sociologia e psicologia." In: social e psicanálise (V. Freitas, trad., p. 71-135). São Paulo: Editora UNESP, 2015.

. FRENKEL-BRUNSWIK, E.; LEVINSON, D. J.; SANFORD, R. N. The authoritarian personality. New York: Harper and Row, 1950.

. SIMPSON, G. "Sobre música popular." In: G. Cohn (Org.), Theodor W. Adorno - Sociologia (p. 115-146). São Paulo: Ática, 1994.

CROCHÍK, J. L. "Tecnologia e individualismo: um estudo de uma das relações contemporâneas entre ideologia e personalidade.” Análise Psicológica. Lisboa, v. 4, n. 17, p. 529-543, 2000.

. "Manifestações de Preconceito em relação às etnias e aos deficientes." Boletim de Psicologia. São Paulo, v. LIII, n. 118, p. 89-108, 2004.

. "Preconceito: relações com a ideologia e com a personalidade." Estudos de Psicologia. Campinas, v. 22, n. 3, p. 309-319, 2005.

. Preconceito, Indivíduo e Cultura (3. ed.). São Paulo: Editora Casa do Psicólogo, 2011.

. CASCO, R.; CERON, M.; CATANZARO, F. O. "Relações entre preconceito, ideologia e atitudes frente à educação inclusiva." Estudos de Psicologia. Campinas, v. 26, p. 123-132, 2009.

. KOHATSU, L. N.; DIAS, M. A.; FRELLER, C. C.; CASCO, R. Inclusão e Discriminação na Educação Escolar, 1. ed. Campinas: Alínea Editora, 2013.

. MASSOLA, G. M.; SVARTMAN, B. P. A ideologia do cientificismo. Psicologia USP [on-line]. São Paulo, v. 26, n. 1, p. 1-3, 2015.

FREUD, S. O mal-estar na civilização. São Paulo: Penguin Classics Companhia das Letras, 2011.

HABERMAS, J. “Técnica e ciência enquanto ideologia." In: Textos escolhidos. Benjamin, Horkheimer, Adorno, Habermas (p. 313-343). São Paulo: Abril Cultural, 1983.

HORKHEIMER, M.; ADORNO, T. W. Temas básicos da sociologia (A. Cabral, trad.). São Paulo: Cultrix, 1973.

de Janeiro: Jorge Zahar, 2006.

Dialética do Esclarecimento: fragmentos filosóficos (G. de Almeida, trad.). Rio KRECH, D; CRUTCHFIELD, R. S.; BALLACHEY, E. L. O Indivíduo na Sociedade - Um manual de Psicologia Social, 3. ed. São Paulo: Pioneira, 1975.

LAPLANCHE, J.; PONTALIS, J.-B. Vocabulário de Psicanálise (P. Tamen, trad.). São Paulo: Livraria Martins Fontes Editora, 1988.

LASCH, C. (1983). A cultura do narcisismo: a vida americana numa era de esperanças em declínio (E. P. Moura, trad.). Rio de Janeiro: Imago, 1983.

MARCUSE, H. Eros e Civilização (A. Cabral, trad.). Rio de Janeiro: Zahar ed., 1981.

MARCUSE, H. Ideologia da Sociedade Industrial (G. Rebuá, trad.). Rio de Janeiro, Zahar ed., 1982. 


\section{ANEXO 1: \\ Escalas}

Instruções:

A seguir, são apresentadas afirmações sobre diversos temas; gostaríamos de saber o grau de sua concordância com cada uma delas. Não há respostas corretas ou incorretas; essas afirmações não expressam, necessariamente, o pensamento dos pesquisadores. Garantimos o anonimato de suas respostas. Pedimos a você que, com a sua primeira impressão, assinale com um "X" o valor da concordância com cada afirmação: o número 1 significa discordância plena e o número 6, concordância plena; quanto maior o número, tanto maior é a concordância.

\begin{tabular}{|c|c|c|c|c|c|c|c|c|}
\hline & Discordo & 1 & 2 & 3 & 4 & 5 & 6 & Concordo \\
\hline $\begin{array}{l}\text { F1. Algum dia se provará que a astrolo- } \\
\text { gia pode explicar muitas coisas. }\end{array}$ & Discordo & & & & & & & Concordo \\
\hline $\begin{array}{l}\text { F2. A obediência e o respeito à autori- } \\
\text { dade são as principais virtudes que de- } \\
\text { vemos ensinar às nossas crianças. }\end{array}$ & Discordo & & & & & & & Concordo \\
\hline $\begin{array}{l}\text { F3. Um indivíduo de más maneiras, } \\
\text { maus costumes e má educação dificil- } \\
\text { mente pode fazer amizade com pes- } \\
\text { soas decentes. }\end{array}$ & Discordo & & & & & & & Concordo \\
\hline $\begin{array}{l}\text { F4. O que este país necessita, primor- } \\
\text { dialmente, antes de leis ou planos po- } \\
\text { líticos, é de líderes corajosos e incansá- } \\
\text { veis em quem o povo possa depositar } \\
\text { a sua fé. }\end{array}$ & Discordo & & & & & & & Concordo \\
\hline $\begin{array}{l}\text { F5. Não se concebe nada pior do que } \\
\text { uma pessoa que não sente profundo } \\
\text { amor, gratidão e respeito por seus pais. }\end{array}$ & Discordo & & & & & & & Concordo \\
\hline $\begin{array}{l}\text { F6. As pessoas podem ser divididas em } \\
\text { duas classes definidas: as fracas e as } \\
\text { fortes. }\end{array}$ & Discordo & & & & & & & Concordo \\
\hline $\begin{array}{l}\text { F7. Só por meio do sofrimento se } \\
\text { aprendem as coisas verdadeiramente } \\
\text { importantes. }\end{array}$ & Discordo & & & & & & & Concordo \\
\hline $\begin{array}{l}\text { F8. A ciência tem o seu lugar, mas há } \\
\text { muitas coisas importantes que a mente } \\
\text { humana jamais poderá compreender. }\end{array}$ & Discordo & & & & & & & Concordo \\
\hline $\begin{array}{l}\text { F9. Às vezes, os jovens têm ideias rebel- } \\
\text { des que, com os anos, deverão superar } \\
\text { para assentar os seus pensamentos. }\end{array}$ & Discordo & & & & & & & Concordo \\
\hline $\begin{array}{l}\text { F10. Se falássemos menos e trabalhás- } \\
\text { semos mais, todos estaríamos melhor. }\end{array}$ & Discordo & & & & & & & Concordo \\
\hline
\end{tabular}




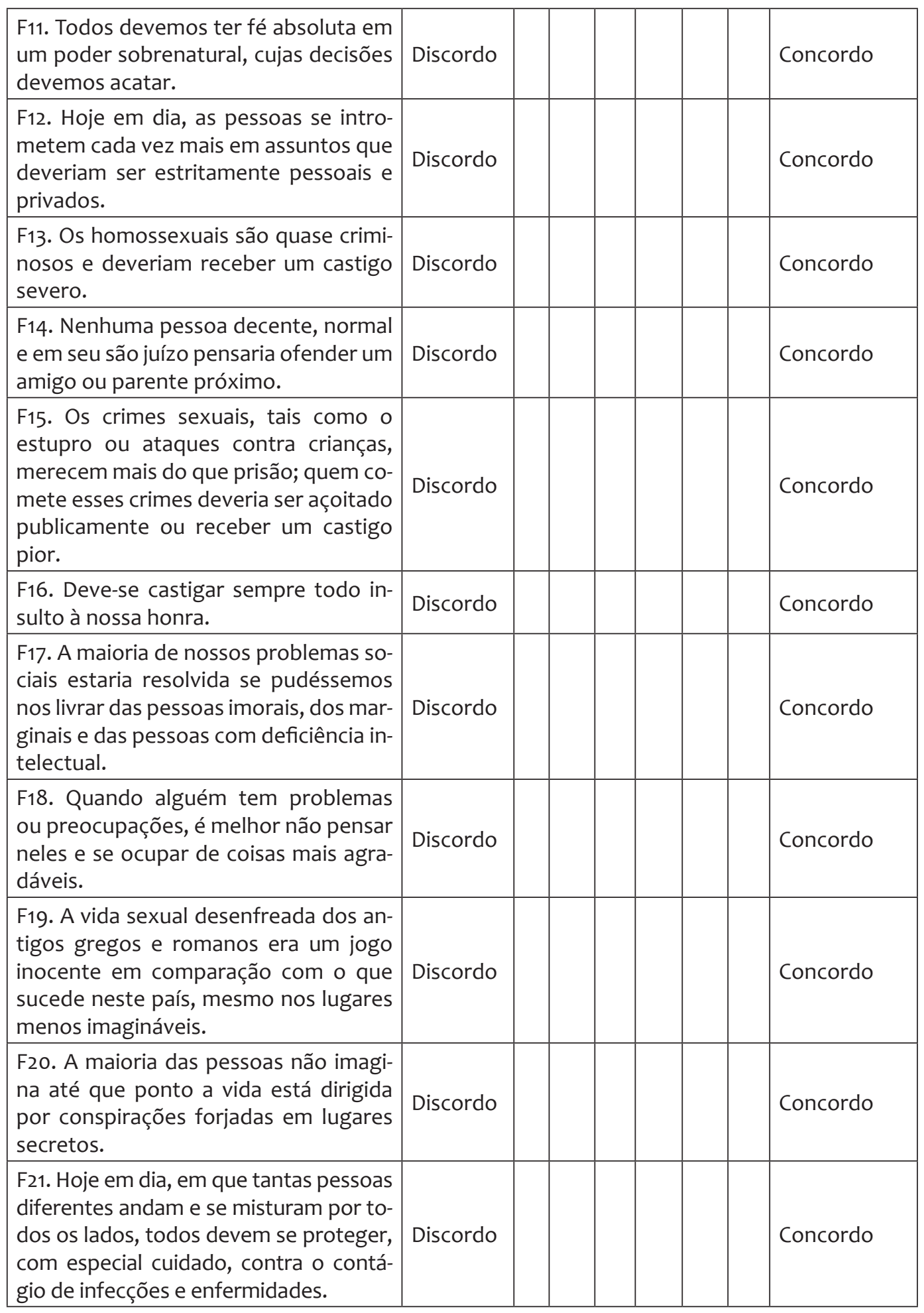




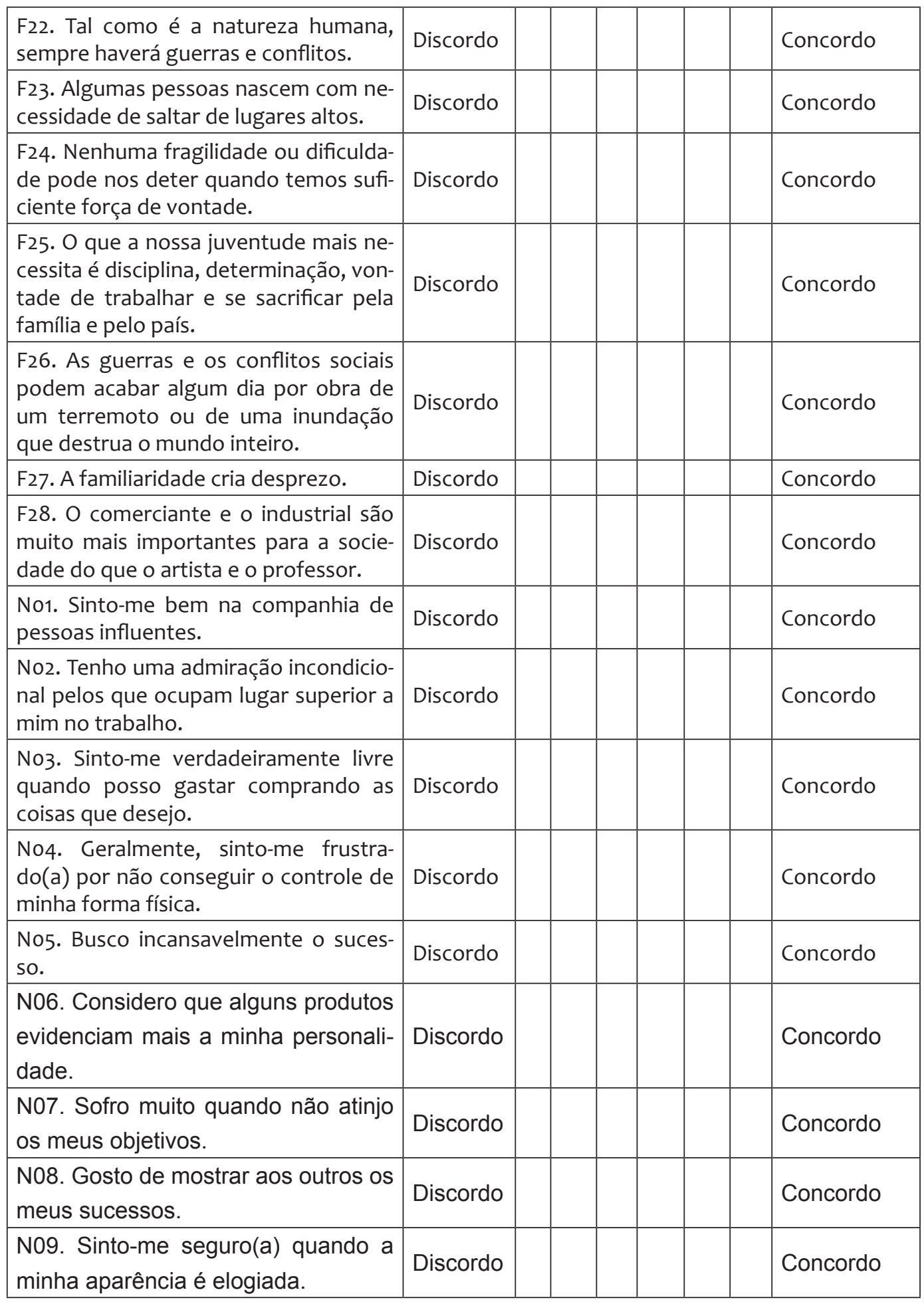




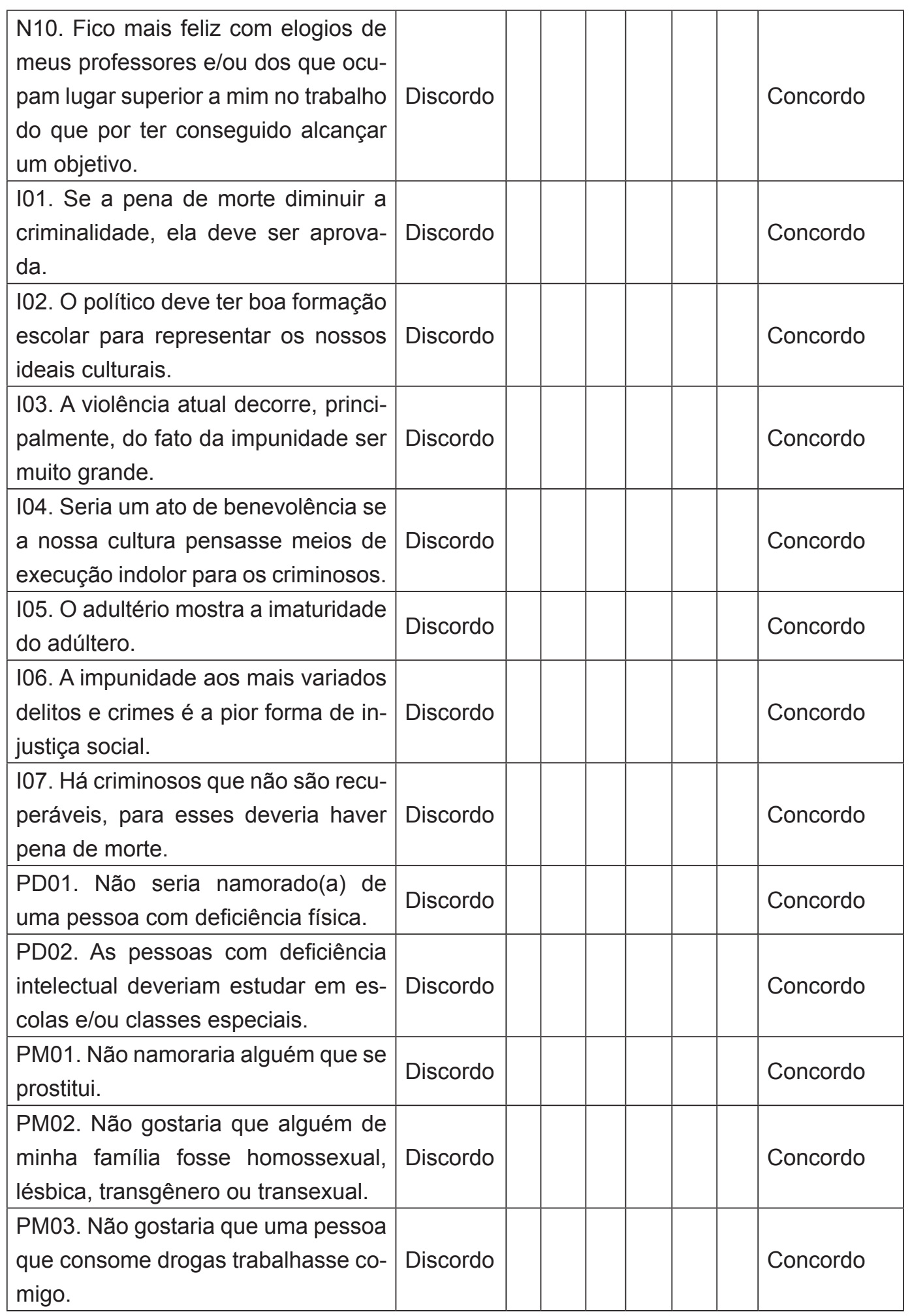




\begin{tabular}{|l|l|l|l|l|l|l|l|l|}
\hline $\begin{array}{l}\text { PM04. Não namoraria pessoa vicia- } \\
\text { da em drogas. }\end{array}$ & Discordo & & & & & & Concordo \\
\hline $\begin{array}{l}\text { PD03. A pessoa com deficiência físi- } \\
\text { ca, na maioria das vezes, lembra-me } \\
\text { a imperfeição humana. }\end{array}$ & Discordo & & & & & & Concordo \\
\hline $\begin{array}{l}\text { PD04. Uma das piores fatalidades } \\
\text { que podem acontecer a uma pessoa } \\
\text { é ter deficiência intelectual. }\end{array}$ & Discordo & & & & & & Concordo \\
\hline $\begin{array}{l}\text { PD05. Geralmente, as pessoas } \\
\text { com deficiência intelectual não são } \\
\text { atraentes. }\end{array}$ & Discordo & & & & & & & \\
\hline $\begin{array}{l}\text { PD06. A presença de uma pessoa } \\
\text { com deficiência intelectual me causa } \\
\text { mal-estar. }\end{array}$ & Discordo & & & & & & & \\
\hline
\end{tabular}

\section{DADOS DO AUTOR}

\section{José LEON CROCHIK}

Doutor em Psicologia Escolar e do Desenvolvimento Humano pela Universidade de São Paulo. Professor Titular do Instituto de Psicologia da Universidade de São Paulo. São Paulo/SP - Brasil. jlchna@usp.br

Submetido em: 28-2-2017

Aceito em: 12-7-2017 